\title{
A RESPONSABILIDADE CIVIL DO FACEBOOK QUANTO ÀS OFENSAS PUBLICADAS POR TERCEIROS: A PROTEÇÃO DO CONSUMIDOR NO ORDENAMENTO JURÍDICO NORTE-AMERICANO E BRASILEIRO.
}

\author{
THE CIVIL LIABILITY OF FACEBOOK AS THE OFFENSES PUBLISHED BY \\ THIRD PARTIES: THE CONSUMER PROTECTION IN THE NORTH-AMERICAN \\ AND BRAZILIAN LEGAL SYSTEM.
}

\author{
${ }^{1}$ Rafaela Bolson Dalla Favera \\ ${ }^{2}$ Rosane Leal da Silva
}

\section{RESUMO}

Este artigo objetiva analisar a responsabilidade civil do Facebook quanto às ofensas publicadas pelos seus usuários. O tratamento do tema nos Estados Unidos, com amparo no método comparativo, analisando se o recente sistema inaugurado pela Lei ${ }^{\circ}$ 12.965/2014 se mostra alinhado às respostas ofertadas naquele país, bem como não colide com as demais normas internas. Constatou-se a tendência nos dois países em isentar o Facebook de responder pelos conteúdos ofensivos publicados por terceiros, opção que no Brasil revela colisão com os princípios protetivos do consumidor, podendo constituir em retrocesso na sua defesa.

Palavras-chave: Código de defesa do consumidor, Communications decency act, Marco civil da internet, Publicações de terceiros, Responsabilidade civil do facebook

\begin{abstract}
This paper aims to analyze the civil liability of Facebook as the offenses published by its users. The treatment of the subject in the United States, with support in the comparative method, analyzing if the recent system inaugurated by Law number $12.965 / 2014$ shows aligned with the answers offered in that country, and does not conflict with other internal rules. It was found the trend in both countries to exempt Facebook to reply from the offensive content published by third parties, option that in Brazil reveals collision with the protective consumer principles, that can constitute a setback in its defense.
\end{abstract}

Keywords: Consumer protection code, Communications decency act, Internet civil mark, Third parties publications, Civil liability of facebook

\footnotetext{
${ }^{1}$ Mestranda em Direito pela Universidade Federal de Santa Maria - UFSM, Rio Grande do Sul (Brasil).

E-mail: rafaeladallafavera@ hotmail.com

${ }^{2}$ Doutora em Direito pela Universidade Federal de Santa Catarina - UFSC, Santa Catarina (Brasil). Professor pela Universidade Federal de Santa Maria - UFSM, Rio Grande do Sul (Brasil). E-mail: rolealdasilva@ gmail.com
} 


\section{INTRODUÇÃO}

Vive-se em momento histórico sem precedentes ditado, em grande parte, pela hiperconexão e pela instantaneidade dos fluxos de informação e comunicação. O crescente uso das Tecnologias da Informação e da Comunicação (TICs), com destaque para a Internet, não apenas promove o desenvolvimento econômico como também dita novas formas de interação social e política, o que contribui para incorporar ao cotidiano de muitas pessoas verbos como publicar e compartilhar conteúdos.

As inovações tecnológicas, no entanto, não têm sido utilizadas apenas para conectar pessoas e promover o acesso a novas fontes de informação. Seu emprego também pode contribuir para a difusão de conteúdos ilícitos e violadores de direitos fundamentais de outras pessoas. Tais práticas não são exclusivas do Brasil, sendo frequentemente noticiadas pela mídia internacional, o que evidencia o caráter global dos conflitos que emergem da sociedade em rede e suscita indagações sobre a eventual responsabilidade civil do site de rede social Facebook, diante da violação de direitos fundamentais de seus consumidores de serviços.

A atualidade, a complexidade e o caráter transnacional da rede mundial de computadores justificam a escolha em estudar o tema a partir do método comparativo, contrastando seu tratamento nos Estados Unidos - um dos países precursores no uso dessa TIC e berço desse site de relacionamento - e no Brasil, país que registra grande número de usuários do Facebook e que apenas recentemente conta com legislação regulamentando o uso da Internet. E este é o ponto no qual se identificam os problemas de pesquisa que nortearão essa investigação: é possível afirmar que o texto do Marco Civil da Internet se mostra alinhado com o tratamento deste tema nos Estados Unidos? E em perspectiva interna, a recente adoção do princípio da inimputabilidade da rede se coaduna com os princípios de proteção do consumidor, consagrados constitucionalmente e tutelados especificamente pelo Código de Defesa do Consumidor?

Considerando a escolha metodológica, para responder a essas indagações dividiu-se o artigo em três partes, sendo que na primeira busca-se analisar o funcionamento dos provedores de hospedagem, explicitando-se a forma de atuação do site de rede social Facebook. Na sequência adentra-se no exame da responsabilidade civil, momento em que se evidencia seu tratamento nos Estados Unidos, berço daquele site de relacionamento para, a partir dessa rápida abordagem, analisar o tratamento jurídico do tema no Brasil. Ao centrar-se na solução recentemente adotada pela Lei $n^{\circ}$ 12.965/2014 (Marco Civil da Internet) o estudo 
culmina em examinar se as respostas ofertadas pela recente legislação se coadunam com os princípios que norteiam a proteção do consumidor.

\section{NOVOS DESAFIOS DA ERA DIGITAL: o funcionamento dos provedores de hospedagem e do site de rede social Facebook.}

A sociedade do Século XXI apresenta configuração que a distingue dos modos de vida, trabalho e interação social até então experimentados: é uma sociedade em rede, pautada na constante conexão e na instantaneidade dos fluxos informacionais cuja transmissão tem nas Tecnologias da Informação e da Comunicação um grande aliado. O uso crescente dessas tecnologias, em especial a Internet, tem provocado uma verdadeira revolução em vários segmentos: relativiza os conceitos de tempo e de espaço ao aproximar ou distanciar pessoas num "clicar do mouse"; promove o desvanecimento das fronteiras geográficas, não respeitadas pela instantaneidade dos fluxos informacionais; converte consumidores passivos de informações em produtores de conteúdos que alimentam blogs e sites de redes sociais com suas postagens diárias, dentre tantas outras transformações que marcam esse período histórico.

Todas essas modificações, típicas de sociedades complexas, não ocorrem sem fraturas, riscos e novas tensões, os quais exigem respostas adequadas ao tempo presente. Esses novos conflitos, além de frequentemente envolverem a colisão de direitos fundamentais no ciberespaço $^{1}$, o que por si só já carrega maior complexidade, ainda impõe o conhecimento mínimo do funcionamento da web, até então ignorado por muitos juristas ${ }^{2}$. Para além de noções estruturais, ainda é preciso compreender que algumas interações sociais ocorridas no ambiente virtual ultrapassam o emissor e o receptor da mensagem, tradicionais atores de qualquer comunicação, abrangendo novos partícipes, os provedores.

Esses novos atores desempenham distintas funções, o que justifica o seu desdobramento em diferentes espécies, quais sejam: provedor de backbone, provedor de acesso, provedor de correio eletrônico, provedor de conteúdo e provedor de hospedagem (LEONARDI, 2005, p.19). Para fins desse trabalho interessa centrar a atenção no provedor de

\footnotetext{
1 Segundo Marcel Leonardi (2012, p.89) "Outro ponto fundamental é a compreensão de que o chamado cyberspace, ou "espaço virtual”, não existe como realidade física. Não é um Estado soberano, mas apenas uma representação audiovisual criada e mantida por sistemas informáticos e programas de computador, presente em quase todos os países do mundo.”.

${ }^{2}$ Nesse contexto algumas diferenciações são importantes para melhor compreender o ambiente virtual como, por exemplo, a de que o World Wide Web ou WWW não se confunde com a Internet, pois não é a mesma coisa. $\mathrm{O}$ $W W W$ é um navegador que se faz necessário para o uso da rede virtual (PAESANI, 2006, p.26).
} 
hospedagem $^{3}$, típico hospedeiro, ou seja, aquele que abriga conteúdos gerados por terceiros. Segundo Marcel Leonardi (2005, p.27), tal provedor caracteriza-se por possuir duas funções distintas, quais sejam, a função de armazenar dados e a função de possibilitar o acesso desses dados a terceiros ${ }^{4}$.

Fachana (2012, p. 31-32) explica que esses sites possuem o que denomina de "atitude proativa" na medida em que estimulam que os utilizadores intensifiquem suas publicações ao oferecer-lhes várias categorias e serviços, tais como disponibilização de espaço para alojamento e partilha de conteúdos em formatos diversos, disponibilização para a criação de bases de dados coletivas, disponibilização de espaço para alojamento de ficheiros, possibilidade de interação em redes sociais, software e partilha de conteúdos entre computadores, dentre outros.

O protagonismo dos utilizadores dos serviços (internautas) é bastante intenso, o que faz com que Fernando Antônio de Vasconcelos (2004, p.72) afirme que os chamados "hospedeiros tecnológicos virtuais" não têm controle sobre o teor daquilo que é publicado nos seus respectivos ambientes virtuais. Dentre esses hospedeiros destacam-se os sites de redes sociais, a exemplo do Facebook ${ }^{5}$, cujo uso é muito difundido entre os internautas de todo o mundo ${ }^{6}$, sendo comum nesse ambiente o registro de colisão entre a liberdade de expressão dos usuários e os direitos fundamentais de outros, como privacidade, intimidade, imagem, honra etc. A colisão entre liberdade e privacidade no ciberespaço não se constitui em novidade, pois Manuel Castells (2007, p.201) conta que no começo os Estados Unidos tentaram controlar o uso da Internet, mas fracassaram, pois a liberdade de expressão encontrava-se protegida constitucionalmente pelos tribunais norte-americanos, sobrepondo-se a outros eventuais direitos. Ao prejudicado caberia, portanto, buscar a indenização que julgasse pertinente.

A grande questão que se coloca, no entanto, é a discussão sobre quem deve responder civilmente pela difusão de conteúdos ilícitos nos sites de relacionamento, especialmente

\footnotetext{
${ }^{3}$ Categoria na qual, segundo Aline Alves Daher (2012, p.11) enquadram-se os sites de relacionamento, dentre eles o Facebook.

${ }^{4}$ Leonardi (2005, p.29) ressalta que é "Importante destacar que o provedor de hospedagem não exerce controle sobre o conteúdo armazenado em seus servidores, o qual é efetuado, em regra, exclusivamente pelos provedores de conteúdo.".

${ }^{5}$ O Facebook foi criado por um estudante de dezenove anos de idade da Universidade de Harvard nos Estados Unidos. Mark Zuckerberg, o criador deste site, cursava ciências da computação naquela instituição e era considerado por muitos um gênio nessa área (KIRKPATRICK, 2011).

${ }^{6}$ Esta rede social ganhou impulso e em 2010 passou a ser o site mais visitado no mundo, depois do Google, com mais de 600 milhões de usuários ativos (KIRKPATRICK, 2011, p.22). De acordo com David Kirkpatrick (2011, p.91) o Facebook é o maior site de rede social do mundo, pois dificilmente um estudante do ensino médio ou da faculdade não tenha um perfil cadastrado naquele ambiente virtual.
} 
considerando a atuação de provedores como o Facebook. É sobre essa temática que versará a próxima seção, que evidenciará o tratamento do tema nos Estados Unidos e no Brasil.

\section{A RESPONSABILIDADE CIVIL DO FACEBOOK EM FACE DAS PUBLICAÇÕES OFENSIVAS REALIZADAS POR TERCEIROS: o estado da questão nos Estados}

\section{Unidos e no Brasil.}

A responsabilidade civil se constitui numa das matérias que recebe mais reflexo das transformações sociais, o que torna seu estudo dinâmico e sempre desafiador ao jurista. Também se trata de um componente curricular que, segundo Garcez Neto (2000, p.1), evidencia maior uniformidade de tratamento em distintos ordenamentos jurídicos, pois segundo ele “[...] os problemas a que dá origem são os mesmos em toda a parte, e se por vezes os pontos de vista teóricos ou técnicos assumem aspectos radicais, todavia as soluções práticas se manifestam quase sempre idênticas em todos os países" (GARCEZ NETO, 2000, p.2), isso porque a maioria das legislações acolhe o princípio neminem laedere, legado romano presente no Corpus Juris Civilis (DONNINNI, 2009, p. 483-503), segundo o qual ninguém está autorizado a causar lesão a esfera jurídica de outra pessoa.

Esse antigo princípio ampara-se na ideia de que a vítima da ação ou omissão da qual resultou prejuízo está autorizada a pleitear a reparação desses danos, busca que só tem se ampliado à medida que as sociedades se tornam mais complexas, pois como explica Garcez Neto (2000, p.18), "O homem dos nossos dias, em face do dano, reage de maneira muito diversa do que ocorria em outras épocas: não se conforma com o mal [...] Daí porque, nos dias que correm, surgem demandas que, antes, a ninguém ocorreria propor".

Dentre as novas demandas que se pode apontar estão aquelas derivadas da publicação e compartilhamento de conteúdos ofensivos e ilícitos em sites de redes sociais, prática que tem se tornado frequente na Internet em várias partes do mundo, com destaque neste estudo para o tratamento do tema nos Estados Unidos e no Brasil.

Previamente cumpre referir que nos Estados Unidos é adotado o sistema jurídico da Common Law, ou seja, a principal fonte de direito deste país são os precedentes jurisprudenciais, ou case laws. Este sistema se utiliza de "políticas públicas de decisão", e não de "regras de decisão", sendo, portanto, um sistema jurídico mais brando. Dessa forma, os juízes norteamericanos possuem liberdade para empregar ou não os casos pretéritos ao feito contemporâneo (CASTRO JR., 2002, p.169). 
Apesar disso, alguns autores como Guido Fernando Silva Soares (2000, p.58) entendem que o sistema adotado pelos Estados Unidos é um sistema misto entre a Common Law e a Civil $\mathrm{Law}^{7}$, pois neste país encontram-se inúmeras leis escritas que devem ser respeitadas e seguidas. Dentre elas, é possível citar a Constituição escrita dos Estados Unidos da América e a Declaração de Direitos, ou Bill of Rights, que são referências importantes e supremas para os americanos. Ainda, encontram-se presentes neste ordenamento jurídico códigos estaduais e federais, além de outras normas (SÈROUSSI, 2001, p.93). Assim, fica claro que nos Estados Unidos as decisões devem ser fundamentadas levando-se em consideração tanto os case laws, quanto as leis escritas.

Nos Estados Unidos a responsabilidade civil é chamada de Tort Law $^{8}$ e foi introduzida naquele ordenamento jurídico há pouco tempo, mais precisamente na segunda metade do Século XX. Surgiu com o intuito de eliminar novos e maiores conflitos que passaram a ocorrer nas relações sociais (VAZ, 2009, p.45). Tal responsabilização resulta da prática de um ato ilícito, assim como no Brasil, visando à reparação do dano sofrido pela vítima. Caroline Vaz (2009, p.49) ensina que este instituto se subdivide em três segmentos, quais sejam: a) Intentional Torts, quando o ato ilícito é praticado propositadamente; b) Negligence, quando o ato ilícito decorre da negligência do seu causador; c) Strict Liability, ou responsabilidade objetiva, quando o ato ilícito provém da inobservância de uma conduta que deve ser sempre seguida, principalmente em atividades de risco.

Quanto à temática da responsabilidade civil decorrente da utilização da Internet constatase o pioneirismo dos Estados Unidos, que não só serviu de berço para o desenvolvimento dessa tecnologia, como também enfrentou os primeiros conflitos derivados de seu uso. Essa realidade forçou o legislador norte-americano a adotar providências muito mais cedo se comparado ao legislador brasileiro, o que fez com que em 1996 passasse a viger naquele país o Communications Decency Act e em 1998 o Digital Millennium Copyright Act, ambos regulamentando o uso da Internet pelos americanos (BINICHESKI, 2011, p.21).

\footnotetext{
${ }^{7}$ Guido Fernando Silva Soares (2000) apresenta em seu livro diversas considerações a despeito dos sistemas jurídicos da Common Law e da Civil Law. Cumpre neste trabalho traçar uma diferenciação conceitual básica entre eles, qual seja: Nos países que adotam a Common Law a principal fonte de direito utilizada são os precedentes jurisprudenciais, já nos países que aderem a Civil Law a principal fonte de direito empregada são as leis escritas. O mesmo autor (SOARES, 2000, p.57) afirma que "Se os juristas e advogados da família romano- germânica olham com certa emulação a adequação dos case laws à realidade, advogados e juristas da Common Law sentem uma certa nostalgia, em face da harmonia e racionalidade dos códigos!".

${ }^{8}$ Segundo Caroline Vaz (2009, p.47) "[...] a Tort Law (responsabilidade civil decorrente de atos ilícitos) objetiva, resumidamente, proteger interesses pessoais e/ou sociais, restabelecendo a(s) pessoa(s), vítima(s) de determinado prejuízo, ao status quo ante (compensatory damages), além de punir o responsável (pessoa física ou jurídica) pela prática do dano causado a essa vítima e dissuadir este e a sociedade em geral de praticar semelhante conduta (punitive damages e exemplary damages).”.
} 
De acordo com Osvaldo Agripino de Castro Jr. (2002, p.155) o termo “Act” designa “[...] as leis expedidas através da cooperação entre Executivo e Legislativo [...]" e o Communications Decency Act destina-se a tratar das informações de caráter difamatório, falso, que envolvam conteúdo explícito para menores e outros, motivo pelo qual será objeto de análise 9 .

O Communications Decency Act de 1996, ou simplesmente CDA, trouxe em seu texto expressamente a imunidade dos Internet Service Providers (ISPS) quanto às publicações ofensivas compartilhadas por terceiros. Paulo Roberto Binicheski (2011, p.32) destaca que esta lei foi criada com o objetivo de proporcionar aos internautas liberdade na transmissão de informações e de ideias por intermédio da rede virtual e, também, incentivar a autorregulação ${ }^{10}$ no ciberespaço com a finalidade de coibir a ocorrência de obscenidades.

Pode-se dizer que a maior contribuição viabilizada pelo $C D A$ quanto à responsabilidade civil dos ISPs foi a seção 230 da referida lei, abaixo transcrita:

(c) (1) No provider or user of an interactive computer service shall be treated as the publisher or speaker of any information provided by another information content provider. (2) No provider or user of an interactive computer service shall be held liable on account of - (A) any action voluntarily taken in good faith to restrict access to or availability of material that the provider or user considers to be obscene, lewd, lascivious, filthy, excessively violent, harassing, or otherwise objectionable, whether or not such material is constitutionally protected; or (B) any action taken to enable or make available to information content providers or others the technical means to restrict access to material described in paragraph (1) (UNITED STATES OF AMERICA, 1996) ${ }^{11}$.

\footnotetext{
${ }^{9}$ O observatório brasileiro de políticas digitais (BRASIL, 2012, p.30) distingue as legislações dizendo que "O CDA, por sua vez, difere do DMCA tanto em seu objeto quanto em sua abordagem sobre a responsabilidade e os incentivos dados às partes envolvidas. Em relação ao objeto, enquanto o DMCA aplica-se a obras intelectuais, ou seja, aquelas protegidas por direitos autorais, o CDA tem por objeto informações de caráter difamatório, falso, que envolvam conteúdo explícito para menores e outros. Aqueles de natureza difamatória são os que mais se assemelham às hipóteses cobertas pelo Marco Civil. Além disso, o CDA proíbe a equiparação dos provedores de serviços a editores para evitar a aplicação da responsabilidade que geralmente incide sobre estes pelo conteúdo publicado.".

${ }^{10}$ A autorregulação na Internet parte da ideia de que esta rede é aberta e potencializa o exercício das liberdades, criando espaços de atuação individual e coletivos que possuem ética e "legalidades" específicas, criadas pelos próprios usuários a partir do costume, dos usos e da netiqueta, o que prescindiria da atuação reguladora do Estado. Assim, pela autorregulação os usuários estabeleceriam as próprias regras, como explicado por Gonçalves (2003, p. 137-142).

11 “(c) (1) Nenhum provedor ou usuário de um serviço de computador interativo será tratado como o editor ou o autor de qualquer informação provida por outro provedor de conteúdo. (2) Nenhum provedor ou usuário de um serviço de computador interativo será responsabilizado por causa de - (A) qualquer ação voluntariamente tomada de boa-fé para restringir o acesso ou disponibilidade de material que o provedor ou usuário considere ser obsceno, libidinoso, lascivo, imoral, excessivamente violento, acedioso, ou censurável, seja ou não tal material protegido constitucionalmente; ou (B) qualquer ação tomada para permitir ou disponibilizar aos provedores de conteúdo de informação e outros os meios técnicos para restringir o acesso ao material descrito no parágrafo (1)." Tradução nossa.
} 
Percebe-se, neste ponto, a preocupação do legislador quanto à proteção dos $I S P S$, para que estes não sejam responsabilizados quando um terceiro publicar materiais ofensivos no ciberespaço, além de facultar-lhes a autorregulação. Cyrus Sarosh Jan Manekshaw (2005, p.107) relata que quase todos os provedores que se utilizaram da seção 230 desta lei obtiveram êxito no sentido de isentarem-se de qualquer responsabilidade quanto às difamações ocorridas na rede virtual. O mesmo autor (MANEKSHAW, 2005, p.109) ressalta que tal imunidade é concedida somente aos provedores, pois aquele que criou e publicou o material ofensivo na rede arcará com as consequências do seu ato, ou seja, será responsabilizado civilmente.

Neste mesmo viés, Paulo Roberto Binicheski (2011, pag.33) destaca que se o material ofensivo não for publicado por um terceiro, mas sim pelo próprio ISP, a responsabilidade civil deste decorrerá das regras gerais do instituto ${ }^{12}$. Na mesma esteira de pensamento, Yasamine Hashemi (2009) complementa este entendimento afirmando que mesmo que os ISPs tenham conhecimento das publicações ofensivas propagadas na rede, não será a eles atribuída qualquer responsabilidade ${ }^{13}$. Isso tudo significa que o Facebook, que é um ISP, está da mesma forma imune. A autora acima citada (HASHEMI, 2009) afirma que o Facebook é considerado um serviço de computador interativo, e que seus usuários podem ser vistos como provedores de conteúdo de informação. Com isso, conclui-se que a rede social está sujeita as imposições e as imunidades outorgadas pelo $C D A$.

Em sentido oposto encontra-se a posição de Richard M. Guo (2008, p.627), que critica esta legislação, pois com ela os provedores não se sentem incentivados a monitorar seus espaços na rede virtual e, por conseguinte, remover materiais ofensivos lá existentes. Em um primeiro momento, o autor esclarece que o CDA, limitando a responsabilidade civil dos ISPs, fez com que os sites de relacionamento prosperassem, pois em situação inversa eles desapareceriam (GUO, p.641). Aprofundando a exposição, este autor afirma a importância da autorregulação $^{14}$ feita pelos referidos sites, em razão de sua vasta experiência com seus

\footnotetext{
${ }^{12}$ De acordo com Paulo Roberto Binicheski (2011, p.34), "Ao elaborar a legislação, o Congresso norteamericano visou garantir o pleno desenvolvimento da internet, em benefício de todos os americanos, com um mínimo de interferência de regulamentos por parte do Governo, tendo isso sido levado ao extremo na interpretação judicial. Desse modo, atuando como intermediários, os ISPs usufruem de ampla imunização por ações de responsabilidade civil.”.

${ }^{13}$ Quanto a isto, Paulo Roberto Binicheski (2011, p.34) afirma que "[...] a imunização alcança situações em que os ISPs poderiam ter impedido a publicação do material difamatório e também quando tomaram inequívoco conhecimento de sua ilicitude, optando por permitir sua continuidade online e, em alguma partida, usufruindo dos lucros advindos da notícia.".

${ }^{14}$ A autorregulação é uma faculdade concedida pelo $C D A$ aos ISPs, e não um requisito obrigatório exigido pela lei. Na verdade, esta autorregulação consiste muito mais em um compromisso dos sites frente aos seus usuários. O próprio site de rede social Facebook, em seu termo de declaração de direitos e responsabilidades
} 
próprios serviços e usuários, além do fato de que tais sites são capazes de desenvolver e implementar medidas rápidas, ao contrário da morosidade característica do Poder Judiciário (GUO, p.643). Em suma, para este autor (GUO, p.644), as medidas de segurança elaboradas pelos sites de redes sociais são relevantes e devem ser aplicadas, assim como o faz o Facebook ao seguir seu termo de declaração de direitos e responsabilidades (FACEBOOK, 2016).

Outra questão controversa e discutida por Paulo Roberto Binicheski (2011, p.38) é o fato de que, não podendo os ISPs serem responsabilizados civilmente pelas ofensas propagadas por terceiros, a vítima deve buscar a reparação do dano na fonte originária, ou seja, daquele que efetivamente disseminou as ofensas no ciberespaço. Isso exige, desde logo, a identificação do ofensor, tarefa que carece da colaboração dos provedores. Ocorre que, nem sempre tais pessoas são identificáveis, pois podem se utilizar de perfis falsos, ou, por vezes, não possuir condições financeiras de arcar com as despesas de uma reparação cível. Assim, frente a qualquer uma dessas situações, o ofendido acaba por não receber qualquer ressarcimento.

Sob a perspectiva da responsabilidade civil o Brasil tem percorrido um interessante caminho desde o modelo ancorado na comprovação da culpa do agente, adotado pelo Código Civil de 1916, até o modelo híbrido da atual legislação civilista, que combina a responsabilidade civil subjetiva (artigo 927, caput) com aquela derivada do risco da atividade (artigo 927, parágrafo único). Ao lado dessa legislação geral deve-se recorrer às soluções previstas pela Lei 8.078, de 1990 - Código de Defesa do Consumidor (CDC), aplicável toda a vez que o problema derivar de uma relação de consumo. Esse instrumento normativo não parecia adequado e suficiente, no entanto, para oferecer soluções aos conflitos que decorriam das interações no ambiente virtual, notadamente aquelas que tinham como palco o Facebook.

Rápida revisão literária sobre o tema permite verificar que alguns autores, a exemplo de Marcel Leonardi (2005, p.176), defendiam que em caso de problemas ali derivados a responsabilidade do provedor de hospedagem era subjetiva e provinha de uma conduta omissiva ou de negligência ou imprudência. Para ser responsabilizado civilmente o provedor de hospedagem deveria ter conhecimento da publicação e certeza quanto a sua ilicitude e, mesmo assim, omitir-se na exclusão do conteúdo ofensivo do ciberespaço. Segundo esse entendimento o provedor de hospedagem não teria controle sobre os conteúdos publicados ou 
compartilhados na rede virtual em função do grande número de usuários (LEONARDI, 2005, p.178). Essa posição também era seguida por Paulo Roberto Binicheski (2011, p.246), que não apenas defendia a responsabilidade subjetiva, como também sustentava que o provedor precisava ser notificado ou ter ciência do material ofensivo compartilhado na rede, só sendo responsabilizado se houvesse omissão de sua parte.

E esses autores não estavam isolados, pois de acordo com a doutrina dominante naquele período a responsabilidade civil do provedor de hospedagem era subjetiva por omissão. A jurisprudência, por sua vez, caminhava na mesma senda, pois o Superior Tribunal de Justiça (STJ) entendia que os sites de relacionamento, assim como o Facebook, deveriam retirar as publicações ofensivas propagadas pelos usuários da rede em até vinte e quatro horas do recebimento da notificação, ou seja, do recebimento de um simples pedido feito pelo usuário. Caso o site não removesse a publicação, estaria sujeito a responder civilmente pelos danos morais sofridos pelo ofendido (OLIVEIRA, 2014), configurando a responsabilidade subjetiva por omissão.

Essa situação se altera com a edição da Lei no 12.965/2014, mais conhecida como Marco Civil da Internet, cujo processo de elaboração notabilizou o Brasil no cenário internacional pelo seu caráter democrático e participativo.

Para a compreensão do princípio da inimputabilidade da rede, um dos grandes princípios que norteiam o Marco Civil da Internet, é necessário destacar os conceitos de provedor de conexão à Internet e provedor de aplicações de Internet. No tex to da lei não é possível encontrar sua definição precisa, mas Frederico Meinberg Ceroy (2014) esclarece que provedor de conexão à Internet é a mesma coisa que provedor de acesso. A dificuldade surge na conceituação do provedor de aplicações de Internet, pois muito embora a legislação não o defina, pode-se dizer que os provedores de correio eletrônico, de hospedagem e de conteúdo são considerados provedores de aplicações de Internet, assim como o site de rede social Facebook, por ser um típico hospedeiro (CEROY, 2014).

Pelo teor do artigo 19 da legislação em comento, os provedores de aplicações somente poderão ser responsabilizados civilmente se, depois de receberem uma ordem judicial específica, não removerem os conteúdos ofensivos disponibilizados por terceiros no ciberespaço. A exceção a esta regra está no artigo 21 do mesmo dispositivo legal, que responsabiliza, de forma subsidiária, os provedores de aplicações quando não removerem materiais publicados por terceiros na Internet que contenham cenas de nudez ou de atos sexuais. Neste caso a simples notificação dos usuários basta para que o provedor sinta-se 
obrigado a remover tais conteúdos, sem a necessidade de uma ordem judicial específica, in verbis:

\begin{abstract}
Art. 19. Com o intuito de assegurar a liberdade de expressão e impedir a censura, o provedor de aplicações de internet somente poderá ser responsabilizado civilmente por danos decorrentes de conteúdo gerado por terceiros se, após ordem judicial específica, não tomar as providências para, no âmbito e nos limites técnicos do seu serviço e dentro do prazo assinalado, tornar indisponível o conteúdo apontado como infringente, ressalvadas as disposições legais em contrário.

[...]

Art. 21. O provedor de aplicações de internet que disponibilize conteúdo gerado por terceiros será responsabilizado subsidiariamente pela violação da intimidade decorrente da divulgação, sem autorização de seus participantes, de imagens, de vídeos ou de outros materiais contendo cenas de nudez ou de atos sexuais de caráter privado quando, após o recebimento de notificação pelo participante ou seu representante legal, deixar de promover, de forma diligente, no âmbito e nos limites técnicos do seu serviço, a indisponibilização desse conteúdo (BRASIL, 2016).
\end{abstract}

Diante desse novo contexto, é possível identificar aspectos positivos e negativos dessa previsão normativa. Como aspecto positivo, pode-se pensar que a exigência de ordem judicial específica para que o provedor de aplicações remova conteúdos ilícitos evitará que essas empresas exerçam um papel de censores, filtrando conteúdos e limitando a liberdade de expressão dos internautas. A previsão do artigo 19 assegura que as limitações à liberdade de expressão (direito fundamental que serve de sustentáculo ao Estado Democrático de Direito) sejam feitas a partir de cuidadoso exame pelo Poder Judiciário, competente para dirimir tais conflitos.

Mas a solução do artigo 19 do Marco Civil da Internet não agrada a todos. Rony Vainzof (2014, p.200), por exemplo, defende a responsabilização civil, pois a partir do momento em que um provedor de aplicações cria um "território", ou seja, um espaço na rede virtual, e constitui um "povoado", também entendido como os usuários desta rede e aufere lucro com seus serviços, não pode se abster dos acontecimentos advindos deste ambiente. $\mathrm{O}$ autor defende que os provedores de aplicações devem agir diante de uma situação em que seus usuários sintamse ofendidos pela difusão de conteúdos ilícitos promovida por outros usuários e, para tanto, devem instaurar um procedimento administrativo, adotando providências dentro da sua autonomia jurídica limitada.

De acordo com Vainzof (2014, p.202), adotando-se as medidas propostas pelo artigo 19 do Marco Civil três situações desvantajosas passarão a ocorrer. Primeiro, as vítimas terão de ajuizar uma ação perante o Poder Judiciário, o que é mais burocrático do que simplesmente denunciar os ilícitos na própria página na Internet. Além disso, o material ofensivo permanecerá on-line até a obtenção da ordem judicial, ou seja, por muito mais tempo, 
agravando o dano já sofrido pela vítima. Tal solução também será inconveniente ao Poder Judiciário que, como se sabe, sofre com o grande número de ações judiciais, sendo que os provedores de aplicações tem plena capacidade de exercer a autorregulação em seus sites.

Ademais, o autor questiona o fato de a nova lei privilegiar o princípio da liberdade de expressão, ser omissa em relação ao anonimato e, em sua opinião, não contemplar de maneira satisfatória o princípio da dignidade da pessoa humana ${ }^{15}$. Complementando suas críticas o autor demonstra que a parte final do caput do artigo 19 do Marco Civil que diz "ressalvadas as disposições legais em contrário" gera uma gama de possibilidades, inclusive para continuar sendo aplicado o entendimento dos tribunais (VAINZOF, 2014, p.204).

Faz-se importante referir que o artigo 19 não proíbe que os provedores de aplicações removam espontaneamente as publicações ofensivas disponibilizadas no ciberespaço por terceiros. Portanto, não há nada que indique que a remoção das publicações ilícitas somente poderá ocorrer por meio de ordem judicial, já que o provedor tem o direito de remover o conteúdo, estando livre para executar suas próprias políticas, conforme consta no termo de declaração de direitos e responsabilidades (FACEBOOK, 2016).

A análise realizada revela que a legislação, no que tange a esse ponto específico, ao regulamentar os atos praticados na Internet acaba colidindo com princípios consagrados no Direito brasileiro para a defesa do consumidor, especialmente quando se trata do reconhecimento da vulnerabilidade e da hipossuficiência desses atores, o que justifica tratamento especial, pautado na boa-fé e no dever de colaboração, conforme se sustentará na sequência.

\section{A RESPONSABILIZAÇÃO DO FACEBOOK NO BRASIL SOB A PERSPECTIVA CONSUMERISTA.}

Muito embora atualmente exista uma lei específica para tratar de assuntos atinentes à Internet, não se podem desconsiderar todos os esforços despendidos pelos doutrinadores para solucionar as lacunas existentes antes da sua entrada em vigor. Da mesma forma não podem ser ignorados os princípios basilares de proteção da integridade física e psíquica do

\footnotetext{
15 Rony Vainzof (2014, p.186) afirma que “[...] no caso de colisão de direitos constitucionais, a nossa Carta Magna primeiramente traz como princípio fundamental a dignidade da pessoa humana, e, posteriormente, como direito e garantia fundamental, a liberdade de pensamento e expressão, com vedação ao anonimato, além da inviolabilidade dos direitos da personalidade, não parecendo coerente e, portanto, passível de inconstitucionalidade, que o art. 19 do Marco Civil priorize e assegure a liberdade de expressão em detrimento, em razão da sua omissão, da dignidade humana, da honra, da intimidade, da vida privada e da vedação ao anonimato.".
} 
consumidor, cuja positivação foi de grande importância para a repersonalização do direito privado.

Como se sabe, o direito do consumidor há muito tempo vem sendo aplicado para a resolução dos problemas emergentes do ciberespaço, e o que se pretende verificar é se tal aplicação ainda é possível após a promulgação do Marco Civil da Internet.

O Código de Defesa do Consumidor (CDC) será empregado sempre que se estiver diante de uma relação de consumo, ou seja, sempre que em uma mesma relação existir a figura do consumidor como destinatário final do produto ou serviço num dos polos da relação jurídica e, no outro extremo, a presença do fornecedor.

Diante dessas informações já é possível perceber que a relação existente entre o site de rede social Facebook e os seus usuários é uma relação de consumo, pois o primeiro oferece um serviço, mediante remuneração indireta, que será adquirido e usufruído pelos segundos, destinatários finais. O que materializa essa relação é o contrato de adesão firmado entre as partes antes da inserção dos usuários no site de relacionamento. Plínio Lacerda Martins (2002, p.80) afirma que o contrato de adesão cria uma relação de confiança entre consumidor e fornecedor, sendo indispensável a boa-fé dos envolvidos.

A característica fundamental dessa relação é a vulnerabilidade do consumidor ${ }^{16}$, que é considerado a parte mais fraca desse elo e que, por isso, merece ser protegido pelo prestador de serviços, de quem espera a observância da boa-fé objetiva ${ }^{17}$, norteadora do direito do consumidor.

Judith Martins Costa (2002, p.640) concede à boa-fé objetiva uma tríplice função, de modo a serem implementados os deveres de solidariedade social dela advindos. A primeira função é a de atuar como cânone hermenêutico e integrativo, auxiliando o intérprete nos casos em que a lei ou o contrato não tragam previsão expressa para regulamentar uma determinada situação. A segunda função derivada da boa-fé objetiva é servir de fonte de deveres jurídicos, tais como os deveres de informação, colaboração, cuidado com os interesses da outra parte, de modo a não lhe causar prejuízos e não frustrar as legítimas expectativas que um contratante deposita no outro em todas as fases da negociação, o que abarca desde o contato social

\footnotetext{
${ }^{16}$ Nas palavras de Claudia Lima Marques (BENJAMIN; MARQUES; BESSA, 2013, p.97) "Vulnerabilidade é uma situação permanente ou provisória, individual ou coletiva, que fragiliza, enfraquece o sujeito de direitos, desequilibrando a relação de consumo. Vulnerabilidade é uma característica, um estado do sujeito mais fraco, um sinal de necessidade de proteção.”.

${ }^{17}$ Esse é um princípio que se aplica a ambos os partícipes da relação jurídica, pois se espera que os envolvidos obrem em respeito recíproco, não quebrando a confiança e as legítimas expectativas depositadas pela outra parte. Nesse ponto a boa-fé objetiva se distingue da tradicional boa-fé subjetiva. Para Plínio Lacerda Martins (2002, p.75) a boa-fé subjetiva "[...] se refere à consciência ou convicção de prática de um ato conforme o direito [...]", já a boa-fé objetiva “[...] se refere a uma regra de conduta que impõe às partes determinado comportamento.”.
} 
(SILVA, 2006), a execução do negócio, até produzir efeitos na etapa pós-contratual. A terceira função da boa-fé objetiva é limitadora, servindo como uma baliza ao exercício de direitos subjetivos na tentativa de evitar o abuso de direito.

Judith Martins Costa (2002, p. 645) ensina que em nome da boa-fé objetiva não se deve frustrar a confiança e as legítimas expectativas existentes entre os contratantes. Este comando é muito importante na presente abordagem, pois se os termos e políticas utilizados pelo Facebook em seu contrato de adesão afirmam que este provedor poderá retirar os conteúdos ofensivos, o internauta que contratou esses serviços e se sentiu lesado com determinadas publicações que violam seus direitos fundamentais (honra, imagem, etc) espera que seja suficiente informar à parte essa situação, recebendo a devida colaboração do site de relacionamento. Portanto, à luz da legislação consumerista parece insustentável supor que o melhor procedimento é ter que recorrer ao Poder Judiciário para obter a colaboração do contratante.

Ademais, a boa-fé coíbe as abusividades contratuais (COSTA, 2002, p.652). Quanto a esta última, pode-se dizer que é abusiva a cláusula contratual que afasta a obrigação de indenizar imputada pelo CDC ao fornecedor (BENJAMIN; MARQUES; BESSA, 2013, p.82). Desse modo é possível pressupor que a cláusula imposta pelo Facebook no sentido de afastar a sua responsabilidade pelos acontecimentos oriundo do site é abusiva.

Tal conjunto argumentativo autorizaria a afirmar que se um usuário informa a publicação e o compartilhamento de conteúdo que viola seus direitos fundamentais o procedimento constitucionalmente adequado seria o Facebook colaborar com a identificação do agressor e com a remoção do material ilícito do site.

Tal procedimento é o esperado porque, diferente da responsabilização imposta pelo Marco Civil da Internet nesses casos, que é subjetiva por omissão e dependente de ordem judicial, o CDC prevê a responsabilidade objetiva para todas as hipóteses de acidentes de consumo, sejam decorrentes de fato do produto ou de fato do serviço, com fulcro na teoria do risco do empreendimento ${ }^{18}$ (CAVALIERI FILHO, 2012, p.514). O CDC prevê em seu artigo 14 , parágrafo $3^{\circ}$, que a responsabilidade não será imputada ao fornecedor de serviços quando este provar que o defeito não existe ou quando a culpa pelo ocorrido for exclusiva do consumidor ou de terceiro (BRASIL, 2016).

\footnotetext{
${ }^{18}$ Conforme Sergio Cavalieri Filho (2012, p.514) "Pela teoria do risco do empreendimento, todo aquele que se disponha a exercer alguma atividade no mercado de consumo tem o dever de responder pelos eventuais vícios ou defeitos dos bens e serviços fornecidos, independentemente de culpa.”.
} 
Até mesmo essas excludentes de responsabilidade podem se revelar frágeis em face da constitucionalização do Direito, em decorrência da qual há a vinculação dos particulares aos direitos fundamentais. Ingo Wolfgang Sarlet (2012, p.385), ao expor o seu entendimento a respeito desta vinculação, afirma que não há problemas na aplicação dos direitos fundamentais que se direcionem de modo direto aos particulares, dando o exemplo da indenização por danos morais no caso de abuso de direito na livre manifestação do pensamento $^{19}$, que se coaduna com este estudo. Para ele os direitos fundamentais devem ter aplicação tanto na ordem pública quanto privada, diante da necessidade de proteção dos particulares frente aos abusos cometidos por outros indivíduos ou entidades privadas (SARLET, 2012, p.387).

Diante de todas essas possibilidades de atribuição de responsabilidade ao Facebook pelos conteúdos ofensivos e ilícitos difundidos pelos seus usuários na rede social, surge o chamado conflito de normas que, desde já, pode ser solucionado pelo denominado diálogo das fontes ou, como prefere Claudia Lima Marques, "modelo brasileiro de coexistência e aplicação simultânea e coerente do Código de Defesa do Consumidor, do Código Civil de 2002 e da legislação especial" (BENJAMIN; MARQUES; BESSA, 2013, p.122). Para esta autora, frente a um conflito de normas, não se deve buscar a exclusão de uma em favor da outra, e sim optar que todas coexistam e sejam aplicadas em conjunto para uma melhor solução dos casos difíceis, sempre atentando aos valores constitucionais e aos direitos fundamentais (BENJAMIN; MARQUES; BESSA, 2013, p.124).

Assim, é possível que duas leis especiais como são o Marco Civil da Internet e o CDC coexistam através de três formas de diálogo das fontes, quais sejam o diálogo sistemático de coerência, diálogo sistemático de complementaridade ou subsidiariedade e diálogo de adaptação ou coordenação (BENJAMIN; MARQUES; BESSA, 2013, p.133). Esse diálogo autoriza que se apliquem as duas leis a um caso concreto, o que é possível a partir do exercício hermenêutico pautado na compreensão dos elementos e desdobramentos da relação jurídica e da utilização (isolada ou combinada) de dispositivos legais que representem a resposta constitucionalmente adequada.

\footnotetext{
${ }^{19}$ Sarlet (2012, p.386) afirma que “[...] a liberdade individual não apenas carece de proteção contra os Poderes públicos, mas também contra os mais fortes no âmbito da sociedade, isto é, os detentores de poder social e econômico, já que é nesta esfera que as liberdades se encontram particularmente ameaçadas, como dão conta, entre tantos outros, os exemplos dos deveres de proteção na esfera das relações de trabalho e a proteção dos consumidores.".
} 


\section{CONCLUSÃO}

É incontestável que as interações sociais realizadas na Internet produzem intensa repercussão no âmbito jurídico, principalmente quando relacionadas às publicações de conteúdos no site de relacionamento Facebook, que é o maior e o mais utilizado no mundo.

Conforme tratado ao longo do artigo, este site se apresenta como um dos intermediários que atuam na Internet, caracterizando-se por possuir duas funções bem definidas, quais sejam, armazenar conteúdos difundidos por seus usuários e permitir o acesso a esses dados pelo próprio autor da publicação e por terceiros, que podem interagir com o material armazenado.

Os problemas ocorrem quando as publicações e/ou compartilhamentos envolvem conteúdos ofensivos e/ou ilícitos que ferem direitos fundamentais de outros, momento em que se estabelece a discussão sobre a possível responsabilidade civil dos provedores que disponibilizam o espaço na web. Esse debate se acirra pelo fato de colocar em confronto duas posições diametralmente opostas: de um lado tem-se a vítima cujos direitos fundamentais (honra, imagem, intimidade) foram violados pela atuação de um terceiro e que espera que o provedor atue em consonância com os ditames da boa-fé objetiva, prestando os deveres de informação acerca do autor da publicação, bem como o auxiliando com a exclusão do conteúdo ofensivo; de outro lado há os interesses econômicos dos grupos que atuam no segmento e que defendem a inimputabilidade da rede, sustentando não terem meios técnicos para exercer o controle sobre as publicações dos seus usuários.

Antes do advento do Marco Civil da Internet a grande maioria dos autores estudados posicionavam-se pela eventual responsabilização dos provedores que hospedavam conteúdo, entendendo que nesse caso a responsabilidade seria subjetiva por omissão, pois somente ocorreria diante da inércia do Facebook em remover os conteúdos ofensivos. Essa posição distanciava o Brasil da solução adotada nos Estados Unidos, onde prevalece o princípio da liberdade de expressão no ciberespaço, com a consequente inimputabilidade civil dos provedores pelos conteúdos publicados e compartilhados pelos internautas.

Conforme visto, naquele país a seção 230 do $C D A$ confere total isenção ao site de rede social Facebook pelas publicações ilícitas viabilizadas por terceiros. Desse modo, a legislação e a doutrina norte-americanas não exigem do provedor a adoção de medidas para tornar indisponíveis os conteúdos ofensivos, evidenciando que o Estado não irá limitar a liberdade de expressão e de comunicação dos internautas ou atribuir responsabilidades aos provedores de hospedagem. 
O Brasil, ante a ausência de lei específica, adotava posição que tentava conciliar o exercício das liberdades com a tutela de outros direitos fundamentais, o que autorizava que os provedores fossem responsabilizados quando, devidamente notificados pela vítima, se omitissem na retirada dos conteúdos ofensivos.

Essa posição pela responsabilidade civil subjetiva por omissão gerava uma série de discussões, especialmente se considerada a relação de consumo que se estabelece entre o provedor e o internauta cujos direitos são violados, já que sua posição de consumidor exige que o provedor observe a boa-fé objetiva, o que implica em colaborar para a pronta exclusão de conteúdos ofensivos e/ou ilícitos. Sob a ótica consumerista e em atenção aos princípios da vulnerabilidade e da boa-fé objetiva, o descumprimento desse dever geraria a responsabilidade civil objetiva.

Em que pese a discussão sobre a espécie de responsabilidade civil a ser aplicada ao caso, o fato é que havia clara inclinação, no Direito brasileiro, pela responsabilização dos provedores de hospedagem. Esse quadro se altera substancialmente com o advento do Marco Civil da Internet, cujo artigo 19 determina que os provedores de aplicações somente deverão agir diante de uma ordem judicial específica de remoção de materiais ilícitos, respondendo civilmente caso se mantenham inertes.

Percebe-se, portanto, que a posição defendida pelos provedores logrou êxito nesse embate de forças, sendo acolhida pelo Marco Civil da Internet a tese da inimputabilidade da rede. Ainda que esta escolha possa parecer vantajosa sob alguns aspectos, sobretudo por não deixar o mercado exercer o papel de "censor" sobre as publicações realizadas pelos internautas, para as pessoas que eventualmente sofram algum tipo de violação de seus direitos fundamentais esta solução não parece satisfatória. Com efeito, se antes bastava a vítima notificar o provedor, agora ela necessitará ajuizar ação judicial perante o Poder Judiciário a fim de obter a eliminação das publicações ofensivas da rede virtual, o que por certo tornará mais morosa a exclusão do conteúdo, ampliando os efeitos danosos.

Assim, além de incentivar a judicialização dos conflitos, a solução adotada pelo Marco Civil da Internet carece de visão sistêmica, pois o teor do artigo 19 revela dissintonia com os princípios que norteiam o Código de Defesa do Consumidor.

O contraste entre as soluções adotadas pela regulação do tema nos dois países investigados permite ver que ambas não amparam suficientemente a vítima lesada, pois enquanto os Estados Unidos consideram o direito à liberdade de expressão como um direito absoluto com proeminência sobre os demais, o Brasil parece ignorar a morosidade do Poder Judiciário em responder às demandas, exigindo que a retirada de conteúdos ofensivos ocorra 
mediante ordem judicial. Desconsidera a necessária tutela do consumidor, assim como também parece ignorar que a velocidade da tecnologia não é a mesma do Direito, pois incontáveis compartilhamentos poderão ocorrer enquanto a vítima ajuíza a ação e obtém a ordem judicial para a retirada dos conteúdos.

A solução legal insatisfatória (sobretudo no caso brasileiro) aumentará a responsabilidade dos juristas, cuja missão será realizar a hermenêutica dessa novel legislação a partir de uma visão constitucionalmente adequada e que privilegie a dignidade da pessoa humana, princípio e valor que deve servir de baliza para nortear as decisões sobre a colisão de direitos fundamentais no ambiente virtual.

\section{REFERÊNCIAS}

BENJAMIN, Antonio Herman V.; MARQUES, Claudia Lima; BESSA, Leonardo Roscoe. Manual de direito do consumidor. 5. ed. São Paulo: Editora Revista dos Tribunais, 2013.

BINICHESKI, Paulo Roberto. Responsabilidade civil dos provedores de internet: direito comparado e perspectivas de regulamentação do direito brasileiro. Curitiba: Juruá, 2011.

BRASIL, Comitê Gestor da Internet no Brasil. Relatório de políticas de internet: Brasil 2011. São Paulo, 2012. Disponível em:

<http://www.cgi.br/media/docs/publicacoes/1/relatorio-politicas-internet-pt.pdf >. Acesso em: 29 fev. 2016.

. Constituição da República Federativa do Brasil. Publicada no Diário Oficial da União n. 191-A, de 5-10-1998. Vade Mecum OAB e concursos. 8. ed. São Paulo: Saraiva, 2016.

Lei 8.078, de 11 de Setembro de 1990. Código de Defesa do Consumidor. Vade Mecum OAB e concursos. 8. ed. São Paulo: Saraiva, 2016.

Lei 10.406, de 10 de Janeiro de 2002. Código Civil. Vade Mecum OAB e concursos. 8. ed. São Paulo: Saraiva, 2016.

Lei 12.965, de 23 de Abril de 2014. Marco Civil da Internet. Vade Mecum OAB e concursos. 8. ed. São Paulo: Saraiva, 2016.

CASTELLS, Manuel. A galáxia da internet: reflexões sobre internet, negócios e sociedade. 2. ed. Lisboa: Fundação Calouste Gulbenkian, 2007.

CASTRO JUNIOR, Osvaldo Agripino de. Teoria e prática do direito comparado e desenvolvimento: Estados Unidos X Brasil. Florianópolis: Fundação Boiteux, UNIGRANRIO, IBRADD, 2002.

CAVALIERI FILHO, Sergio. Programa de responsabilidade civil. 10. ed. São Paulo: Atlas, 2012. 
CEROY, Frederico Meinberg. Os conceitos de provedores no Marco Civil da Internet. Jus Navigandi, Teresina, ano 19, n. 4093, 15 set. 2014. Disponível em:

<http://jus.com.br/artigos/31938/os-conceitos-de-provedores-no-marco-civil-da-internet>. Acesso em: 29 fev. 2016.

COSTA, Judith Martins. Mercado e solidariedade social entre cosmos e taxis: a boa-fé nas relações de consumo. In: COSTA, Judith Martins (Org.). A reconstrução do direito privado. São Paulo: Editora Revista dos Tribunais, 2002, p.611-661.

DAHER, Aline Alves. A responsabilidade civil dos provedores de hospedagem da internet. 2012. Artigo Científico apresentado como exigência de conclusão de Curso de PósGraduação Lato Sensu da Escola da Magistratura do Estado do Rio de Janeiro. Rio de Janeiro, 2012. Disponível em:

<http://www.emerj.tjrj.jus.br/paginas/trabalhos_conclusao/1semestre2012/trabalhos_12012/al inealvesdaher.pdf>. Acesso em: 29 fev. 2016.

DONNINI, Rogério. Prevenção de danos e a extensão do princípio neminem laedere. In: NERY, Rosa Maria de Andrade; DONNINNI, Rogério; MALUF, Adriana Caldas do Rego Freitas Dabus Maluf. [et al.]. Responsabilidade civil: estudos em homenagem ao professor Rui Geraldo Camargo Viana. São Paulo, Revista dos Tribunais, 2009, p. 483-503.

FACEBOOK. Termos e Políticas do Facebook: tudo o que você precisa saber em um só lugar. 2016. Disponível em: 〈https://pt-br.facebook.com/policies/>. Acesso em: 29 fev. 2016.

FACHANA, João. Responsabilidade civil pelos conteúdos ilícitos colocados e difundidos na internet. Coimbra: Edições Almedina, 2012.

GARCEZ NETO, Martinho. Responsabilidade civil no direito comparado. Rio de JaneiroSão Paulo: Renovar, 2000.

GONÇALVES, Maria Eduarda. Direito da informação: novos direitos e formas de regulação na sociedade da informação. Coimbra: Almedina, 2003.

GUO, Richard M.. Stranger danger and the online social network. Berkeley Technology Law Journal. Berkeley - USA, 2008. Disponível em:

<http://scholarship.law.berkeley.edu/cgi/viewcontent.cgi?article $=1742 \&$ context $=b t l j>$. Acesso em: 29 fev. 2016.

HASHEMI, Yasamine. Facebook's privacy policy and its third-party partnerships: lucratively and liability. Journal of Science and Technology Law. Boston - USA, 2009. Disponível em:

<http://www.bu.edu/law/central/jd/organizations/journals/scitech/volume151/documents/Hash emi_WEB.pdf>. Acesso em: 29 fev. 2016.

KIRKPATRICK, David. O efeito Facebook: os bastidores da história da empresa que conecta o mundo. Livro digital. Rio de Janeiro: Intrínseca, 2011.

LEONARDI, Marcel. Internet: elementos fundamentais. In: SILVA, Regina Beatriz Tavares da; SANTOS, Manoel J. Pereira dos (coords.). Responsabilidade civil na internet e nos demais meios de comunicação. São Paulo: Saraiva, 2012, p.79-95. 
. Responsabilidade civil dos provedores de serviços de internet. São Paulo: Juarez de Oliveira, 2005.

MANEKSHAW, Cyrus Sarosh Jan. Liability of ISPs: immunity from liability under the Digital Millenium Copyright Act and the Communications Decency Act. SMU Computer Law Review and Technology Journal. USA, 2005. Disponível em: $<$ http://studentorgs.law.smu.edu/Science-and-Technology-Law-Review/Articles/Summer2007/SMC103.aspx>. Acesso em: 29 fev. 2016.

MARTINS, Plínio Lacerda. O abuso nas relações de consumo e o princípio da boa-fé. Rio de Janeiro: Forense, 2002.

OLIVEIRA, Carlos Eduardo Elias de. Aspectos principais da Lei $\mathbf{n}^{\circ}$ 12.965, de 2014, o Marco Civil da Internet: subsídios à comunidade jurídica. Brasília: Núcleo de estudos e pesquisas/CONLEG/Senado, abr./2014 (texto para discussão $n^{\circ} 148$ ). Disponível em: <http://www12.senado.gov.br/publicacoes/estudos-legislativos/tipos-de-estudos/textos-paradiscussao/td-148-aspectos-principais-da-lei-no-12.965-de-2014-o-marco-civil-da-internetsubsidios-a-comunidade-juridica>. Acesso em: 29 fev. 2016.

PAESANI, Liliana Minardi. Direito e internet: liberdade de informação, privacidade e responsabilidade civil. 3. ed. São Paulo: Atlas, 2006.

SARLET, Ingo Wolfgang. A eficácia dos direitos fundamentais: uma teoria geral dos direitos fundamentais na perspectiva constitucional. 11. ed. Porto Alegre: Livraria do Advogado Editora, 2012.

SÈROUSSI, Ronald. Introdução ao direito inglês e norte americano. São Paulo: Landy, 2001.

SILVA, Clóvis do Couto. A obrigação como processo. Rio de Janeiro: Editora FGV, 2006. SOARES, Guido Fernando Silva. Common law: introdução ao direito nos EUA. 2. ed. São Paulo: Revista dos tribunais, 2000.

UNITED STATES OF AMERICA. Communications Decency Act of 1996. In Telecommunications Act of 1996. Disponível em: <http://www.gpo.gov/fdsys/pkg/PLAW104publ104/pdf/PLAW-104publ104.pdf >. Acesso em: 29 fev. 2016.

VAINZOF, Rony. Da responsabilidade por danos decorrentes de conteúdo gerado por terceiros. In: MASSO, Fabiano Dolenc Del; ABRUSIO, Juliana; FLORÊNCIO FILHO, Marco Aurélio (Coords.). Marco Civil da Internet: Lei 12.965/2014. São Paulo: Editora Revista dos Tribunais, 2014, p.177-205.

VASCONCELOS, Fernando Antônio de. Internet: responsabilidade do provedor pelos danos praticados. 1. ed. Curitiba: Juruá, 2004.

VAZ, Caroline. Funções da responsabilidade civil: da reparação à punição e dissuasão: os punitive damages no direito comparado e brasileiro. Porto Alegre: Livraria do Advogado, 2009. 